\title{
Comparison of Sleep Spindles and Theta Oscillations in the Hippocampus
}

\author{
David Sullivan, ${ }^{1,2}$ Kenji Mizuseki, ${ }^{1,2}$ Anthony Sorgi, ${ }^{1}$ and György Buzsáki ${ }^{1,2}$ \\ ${ }^{1}$ Center for Molecular and Behavioral Neuroscience, Rutgers, The State University of New Jersey, Newark, New Jersey 07102 , and ${ }^{2}$ Neuroscience Institute, \\ School of Medicine, New York University, New York, New York 10016
}

\begin{abstract}
Several network patterns allow for information exchange between the neocortex and the entorhinal-hippocampal complex, including theta oscillations and sleep spindles. How neurons are organized in these respective patterns is not well understood. We examined the cellular-synaptic generation of sleep spindles and theta oscillations in the waking rat and during rapid eye movement (REM) sleep by simultaneously recording local field and spikes in the regions and layers of the hippocampus and entorhinal cortex (EC). We show the following: (1) current source density analysis reveals that similar anatomical substrates underlie spindles and theta in the hippocampus, although the hippocampal subregions are more synchronized during spindles than theta; (2) the spiking of putative principal cells and interneurons in the CA1, CA3, and dentate gyrus subregions of the hippocampus, as well as layers 2, 3, and 5 of medial EC, are significantly phase locked to spindles detected in $\mathrm{CA1}$; (3) the relationship between local field potential (LFP) phase and unit spiking differs between spindles and theta; (4) individual hippocampal principal cells generally do not fire in a rhythmic manner during spindles; (5) power in gamma $(30-90 \mathrm{~Hz})$ and epsilon $(>90 \mathrm{~Hz})$ bands of hippocampal LFP is modulated by the phase of spindle oscillations; and (6) unit firing rates during spindles were not significantly affected by whether spindles occurred during non-REM or transitions between non-REM and REM sleep. Thus, despite the similar current generator inputs and macroscopic appearance of the LFP, the organization of neuronal firing patterns during spindles bears little resemblance to that of theta oscillations.
\end{abstract}

Key words: entorhinal cortex; gamma; hippocampus; sleep; spindle; theta

\section{Introduction}

Sleep spindles in the neocortex are among the most prominent features of non-rapid eye movement (REM) sleep (Loomis et al., 1935; Steriade et al., 1993a; De Gennaro and Ferrara, 2003). Spindles have been implicated in synaptic plasticity and sleepdependent memory consolidation in both humans and other animals(Sejnowski and Destexhe, 2000; Steriade, 2000; Gais et al., 2002; Schiffelholz and Aldenhoff, 2002; Miyamoto and Hensch, 2003; Steriade and Timofeev, 2003; Khazipov et al., 2004; Schabus et al., 2004; Eschenko et al., 2006; Hanlon et al., 2009; Diekelmann and Born, 2010; Fogel and Smith, 2011; Nir et al., 2011), partly because of the ability of thalamocortical spindles to trigger hippocampal sharp wave ripples (Siapas and Wilson, 1998; Sirota et al., 2003; Isomura et al., 2006; Mölle et al., 2006; Clemens et al., 2007, 2010; Nishida and Walker, 2007; Eschenko et al., 2008; Peyrache et al., 2009, 2011; Johnson et al., 2010; Sullivan et al., 2011). Altered sleep spindle dynamics have been documented in several forms of mental disease (Ferrarelli et al., 2007, 2010; Vu-

\footnotetext{
Received Feb. 5, 2013; revised Nov. 21, 2013; accepted Nov. 26, 2013.

Author contributions: D.S., K.M., and G.B. designed research; D.S., K.M., and A.S. performed research; D.S. analyzed data; D.S. and G.B. wrote the paper.

This work was supported by National Institutes of Health Grants NS034994 and MH54671 (J.D.), the McDonnell Foundation, and the National Science Foundation (Temporal Dynamics of Learning Center Grant SBE 0542013). We thank members of the Buzsáki laboratory for their comments on this manuscript.

Correspondence should be addressed to György Buzsáki, Neuroscience Institute, School of Medicine, New York University, East River Science Park, 450 East 29th Street, New York, NY 10016. E-mail: gyorgy.buzsaki@nyumc.org. DOI:10.1523/JNEUROSCI.0552-13.2014

Copyright $\odot 2014$ the authors $\quad 0270-6474 / 14 / 340662-13 \$ 15.00 / 0$
}

kadinovic, 2011; Wamsley et al., 2012; Wilson and Argyropoulos, 2012; Plante et al., 2013). However, it is not clear whether thalamocortical spindles regularly invade the hippocampus and affect its circuits outside sharp wave ripples, although several observations suggest that this might be the case (Sirota et al., 2003; Isomura et al., 2006; Nir et al., 2011).

Sleep spindles are generated by the interaction between the GABAergic neurons of the thalamic reticular nucleus and the thalamocortical nuclei (Steriade et al., 1993b; Steriade, 2000; Astori et al., 2011; Halassa et al., 2011) and are synchronized across the multiple thalamic nuclei via neocortical feedback (Contreras et al., 1996; Gottselig et al., 2002). Sleep spindles can reach the hippocampus by either the direct projection from nucleus reuniens to the distal dendrites of CA1 pyramidal (Herkenham 1978; Wouterlood et al., 1990; Dolleman-Van der Weel et al., 1997) or the neocortical-entorhinal cortex (EC) path (Isomura et al., 2006; Wolansky et al., 2006; Hahn et al., 2007). If the EC is involved in conveying the neocortical rhythm to the circuits of the hippocampus, a comparison with the mechanisms of theta oscillations is warranted because most theta-associated currents are also generated by the entorhinal inputs (Buzsáki et al., 1983; Alonso and Llinás, 1989; Bragin et al., 1995; Chrobak and Buzsáki, 1998; Kamondi et al., 1998; Montgomery et al., 2009) but in a different brain state. In the present experiments, we investigated the physiological features of sleep spindles and compared their cellular-synaptic generation with those of the theta oscillations in REM sleep and the waking rat. We report that, although the 


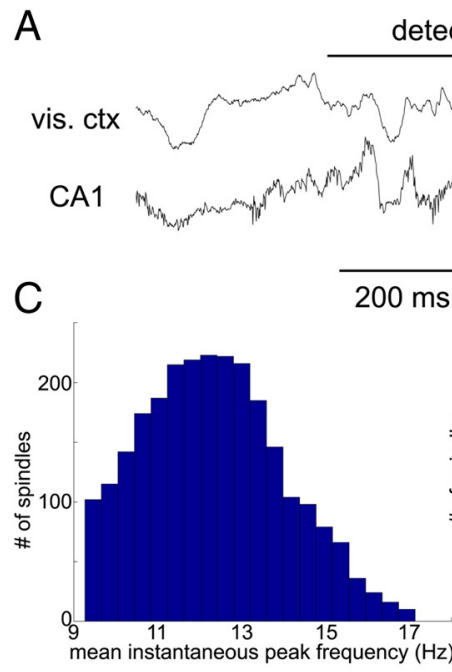

detected spindle
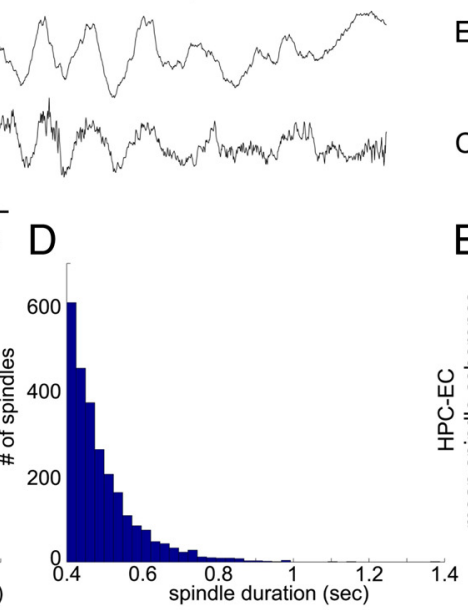

B
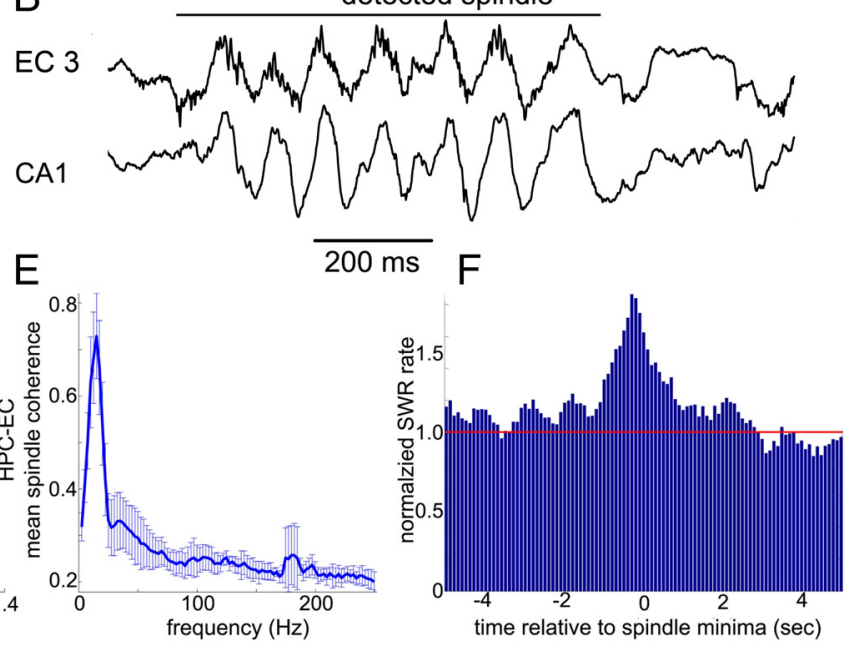

Figure 1. Basic features of sleep spindles. $A$, Example of filtered (1-626 Hz) LFP traces of a spindle event recorded simultaneously in the hippocampal CA1 pyramidal layer and visual cortex (vis. ctx). $\boldsymbol{B}$, Example of filtered (1-625 Hz) LFP traces of a spindle event recorded simultaneously in the hippocampal CA1 pyramidal layer and layer 3 of medial EC. Note the similar onset, offset, and duration of the spindles in different structures. $C$, Histogram of mean instantaneous peak frequency of spindles recorded and detected in the hippocampal CA1 pyramidal layer (mean of $12.33 \mathrm{~Hz}$, $n=2579$ spindles in 15 rats). $\boldsymbol{D}$, Histogram of spindle duration (mean of 0.49 s). $\boldsymbol{E}$, Average coherence spectrum between spindles in the CA1 pyramidal layer and layer 5 of the $\mathrm{EC}(n=8$ sessions in 2 rats; error bars indicate SEM). Note the peak coherence value at $15 \mathrm{~Hz}$. F, Cross-correlogram between LFP spindle minima and detected SWR events in hippocampal CA1 shows temporal association of these two patterns, peaking at $300 \mathrm{~ms}$ preceding individual spindle troughs in CA1, with SWR occurrence rate at 187\% of baseline ( $n=23$ sessions in 14 rats).

anatomical substrates underlying the extracellular current generation of both rhythms are similar, the temporal organization of neuronal firings are qualitatively different during theta and spindle oscillations.

\section{Materials and Methods}

Animals and surgery. Fifteen male Long-Evans rats and one male Sprague Dawley rat (350-500 g; 5-8 months old) were used in these experiments; behavioral training, surgery details, and data obtained from all but three of the present rats have been reported previously (Csicsvari et al., 2003; Diba and Buzsáki, 2007; Mizuseki et al., 2009; Montgomery et al., 2009; Fujisawa and Buzsáki, 2011; Sullivan et al., 2011). After maze training, recording electrodes were implanted, and, in some of the rats in which electrodes targeted the dentate gyrus, bipolar perforant path stimulation electrodes were implanted for anatomical localization (Montgomery et al., 2008). In five rats, a 96-site silicon probe was implanted in the right hemisphere parallel to the transverse axis of the hippocampus $\left(45^{\circ}\right.$ parasagittal). These probes had recording sites spaced regularly over a $1.5 \times$ $1.5 \mathrm{~mm}^{2}$ area with six shanks spaced at $300 \mu \mathrm{m}$, each with 16 recording sites at $100 \mu \mathrm{m}$ spacing. A bipolar stimulating electrode was implanted into the angular bundle (perforant path) at $1.0 \mathrm{~mm}$ anteroposterior (AP) and $1.0 \mathrm{~mm}$ mediolateral (ML) from the junction between lambda and the right lateral ridge, and $3.5 \mathrm{~mm}$ dorsoventral from the dura. Another stimulating electrode was implanted in the ventral hippocampal commissure at $1.2 \mathrm{~mm} \mathrm{AP}$ and $1.0 \mathrm{~mm}$ ML from bregma and $3.8 \mathrm{~mm}$ from the dura (Csicsvari et al., 2000; Montgomery et al., 2009). Four rats were implanted with 32- and/or 64-site silicon probes in the left or right dorsal hippocampus. The silicon probes, consisting of four or eight individual shanks (spaced $200 \mu \mathrm{m}$ apart), each with eight staggered recording sites (20 $\mu \mathrm{m}$ spacing), were lowered to CA1 and CA3 pyramidal cell layers (Diba and Buzsáki, 2007) and dentate gyrus. An additional three rats were implanted with a four-shank silicon probe in the right dorsocaudal medial EC and another four- or eight-shank probe into the CA1-dentate axis (Mizuseki et al., 2009). One rat was implanted only with a fourshank silicon probe in the right dorsocaudal medial EC (Mizuseki et al., 2009). Two rats were implanted with three tetrode microdrives (individually movable tetrodes constructed from $13 \mu \mathrm{m}$ tungsten wire): (1) one microdrive with three tetrodes targeting right dorsal hippocampal CA1; (2) one microdrive with four tetrodes targeting the right visual cortex; and (3) one microdrive with one tetrode targeting the medial septum. One rat was implanted with a four-shank silicon probe in the right dorsal hippocampal CA1 and an eight-shank probe in the PFC (Fujisawa and Buzsáki, 2011). Two stainless steel screws inserted above the cerebellum were used as indifferent and ground electrodes during recordings.

Postmortem electrode location was verified using thionin, fluorescent Nissl (Invitrogen), or DAPI (Invitrogen) staining in combination with DiI-labeled (Invitrogen) electrode tracks. Histological reconstruction of electrode tracks is available from the studies by Montgomery and Buzsáki (2007), Diba and Buzsaki (2008), Montgomery et al. (2008), Mizuseki et al. (2009), and Fujisawa and Buzsáki (2011). All protocols were approved by the Institutional Animal Care and Use Committee of Rutgers University.

Data collection. After recovery from surgery ( $\sim 1$ week), physiological signals were recorded in the home cage and included waking immobility and sleep epochs. During sleep, the rat curled up in one of the corners with its eyes closed. REM and slow-wave sleep epochs were separated as described previously (Montgomery and Buzsáki, 2007; Montgomery et al., 2008; Grosmark et al., 2012). In addition, we analyzed recordings obtained while the animal ran on an open field $(200 \times 100 \mathrm{~cm}, 180 \times 180$ $\mathrm{cm})$, a linear maze ( $250 \mathrm{~cm}$ long), and an alternation task in the T-maze (Montgomery and Buzsáki, 2007; Mizuseki et al., 2009). Theta periods from all maze behaviors were lumped together as RUN. During the recording sessions, neurophysiological signals were amplified $(1000 \times)$, bandpass filtered ( $1 \mathrm{~Hz}$ to $5 \mathrm{kHz}$ ), and acquired continuously at $20 \mathrm{kHz}$ on a 128-channel DataMax system (RC Electronics) or at $32.552 \mathrm{kHz}$ on a 128-channel Digital Lynx system (Neuralynx). After recording, the local field potential (LFP) was downsampled to $1250 \mathrm{~Hz}$ (DataMax) or $1252 \mathrm{~Hz}$ (Neuralynx) for additional analysis. For offline spike sorting of unit activity, the wideband signal was digitally high-pass filtered $(0.8-5$ $\mathrm{kHz}$ ). Spike sorting was performed automatically, using KlustaKwik (http://klustakwik.sourceforge.net), followed by manual adjustment of the clusters (using "Klusters" software package; http://klusters.sourceforge. net). Neurophysiological and behavioral data were explored using NeuroScope (http://neuroscope.sourceforge.net) (Hazan et al., 2006). Additional details of recording and unit separation and cell-type classifications have been described previously by Csicsvari et al. (2003), Diba and Buzsáki (2007), and Mizuseki et al. (2009). For the entorhinal unit data here, putative interneurons and principal cells were classified according to the procedure described by Mizuseki et al. (2009). Because of the low number of simultaneously recorded hippocampal units in animals implanted with 96-site probes, we used a simplified method for classification of hippocampal units based on the shape of spike autocorrelograms; units 
with a characteristic "bursty" autocorrelogram were classified as principal cells, and units lacking a "bursty" autocorrelogram with mean firing rates $>5 \mathrm{~Hz}$ were classified as putative interneurons. Hippocampal units with mean firing rates $<0.1 \mathrm{~Hz}$ were discarded from the dataset. Recording site irregularities (including crosstalk and excessive impedances) were a priori identified and removed from analysis using measures of coherence and normalized power similarity (Diba et al., 2005). Current source density (CSD) was calculated by standard methods (Mitzdorf, 1985). Only CSD calculations centered on three consecutive good channels were used. CSD calculations that would require use of a recording site displaying an irregularity were excluded from additional analysis.

Wavelet algorithm. For wavelet analysis, the discrete wavelet transform (65 levels, 1-300 $\mathrm{Hz}$ ) was computed by using a MATLAB wavelet software package provided by C. Torrence (ITT Visual Information Solutions, Boulder, $\mathrm{CO}$ ) and G. Compo (National Oceanic and Atmospheric Administration/Cooperative Institute for Research in Environmental Sciences Climate Diagnostics Center, University of Colorado, Boulder CO) (http://paos.colorado. edu/research/wavelets/software.html). For every channel subjected to wavelet analysis, power and phase were calculated and saved for each level (i.e., frequency) for each sample (either 1250 or $1252 \mathrm{~Hz}$ ) for the entire length of the recording. Power at each level (i.e., frequency) of the wavelet transform was individually normalized by the mean and SD of wavelet power during non-REM episodes. Although the wavelet data for the entire session were normalized, only data from non-REM sleep epochs were used to calculate the normalizing factors to avoid bias deriving from differing proportions of nonREM sleep and other behaviors in recording sessions. For each unit spike in the datasets, phase relative to a rhythm of interest was calculated by finding the wavelet phase at the frequency with the highest normalized wavelet power within a specified range of frequencies (theta, 4.95-10.02 Hz; spindle, 9.27-17.34 Hz).

Detection of ripples. Ripples were detected via the following procedure: from a single LFP channel in the CA1 pyramidal layer, we calculated mean normalized wavelet power between 97.05 and $196.33 \mathrm{~Hz}$ for every sample in the recording. This signal was then smoothed with a 40-ms-wide uniform window and then $z$-score normalized. Ripples were defined as epochs during which this $z$-score normalized signal was at least $2.5 \mathrm{SDs}$ above the mean for a duration of at least $30 \mathrm{~ms}$.

Detection of spindles. Spindles were detected via the following procedure, which is essentially the same as described by Johnson et al. (2010): from a single LFP channel in the CA1 pyramidal layer (if available, otherwise entorhinal layer 5 or dentate molecular layer), we calculated the maximum normalized wavelet power in frequencies between 9.27 and 17.34 $\mathrm{Hz}$ for every sample in the recording. This signal was then $z$-score normalized, and epochs in
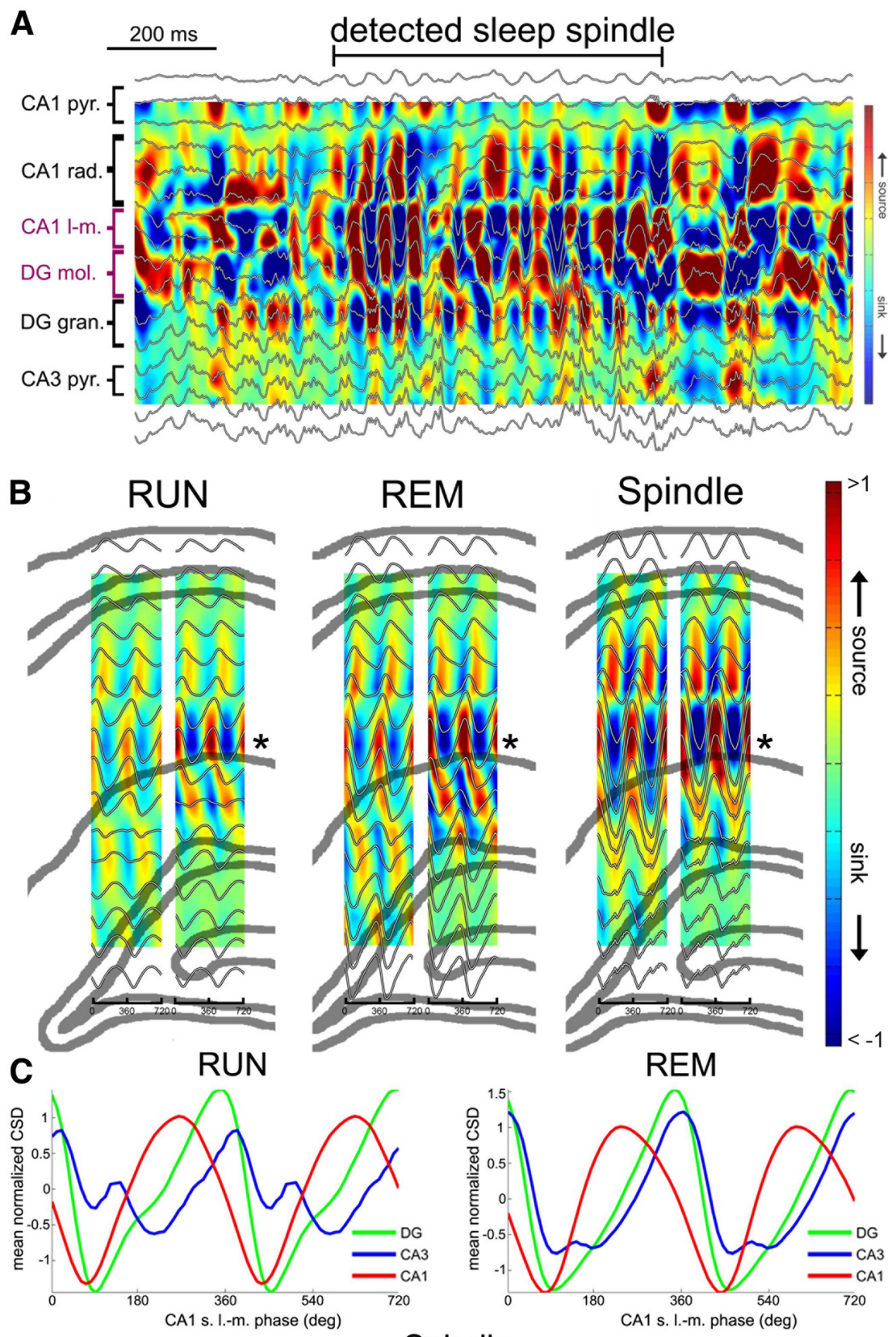

Spindle

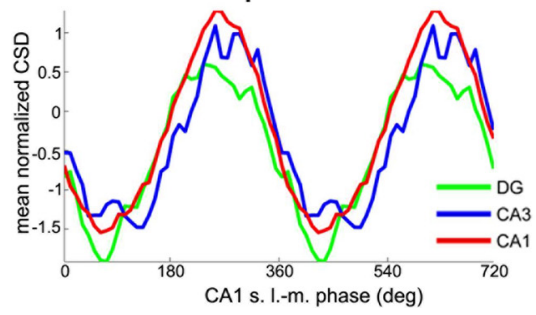

Figure 2. Spindleand theta oscillations in the hippocampus. A, Example of wideband (1 Hzto $1250 \mathrm{~Hz})$ LFP traces of a spindle event, recorded at multipledepths of the CA1 - dentate axis and superimposed on theCSD map of the same event. CA1 pyr, Pyramidal layer; CA1 rad, stratum radiatum; CA1 I-m, stratum lacunosum-moleculare; DG mol, dentate gyrus molecular layer; DG gran, granule cell layer; CA3 pyr, pyramidal layer in the hilar region. $B$, Average CSD maps in a single animal with superimposed LFP traces during RUN, REM, and spindle. Recordings from two shanks of the silicon probe are shown. Maps and traces were constructed by averaging CSD and LFP traces according to CSD phase in CA1 stratum lacunosummoleculare (phase was partitioned into $10^{\circ}$-wide bins). Asterisk indicates reference site. The cycles are calibrated in degrees rather than in time to emphasize the similar depth distributions of the sinks and sources during theta and spindle waves. The same CSD color scale was used in RUN, REM, and spindle plots; CSD units are relative and arbitrary because tissue impedance was not measured. C, Averagenormalized CSD as a function of phase in the three hippocampal principal cell layers ( $n=5$ sessions in 5 rats). Values $>0$ are sources, whereas values $<0$ are sinks. Note the enhanced synchrony of CSD in the CA1, CA3, and dentate principal cell layers during spindle oscillations relative to REM or RUN theta. 
A
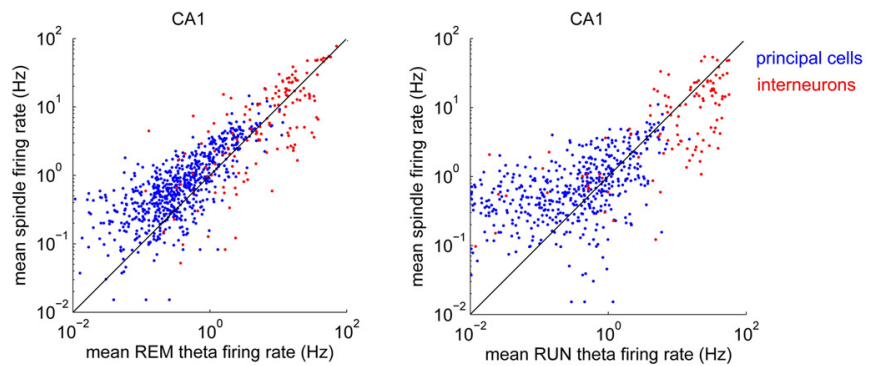

B
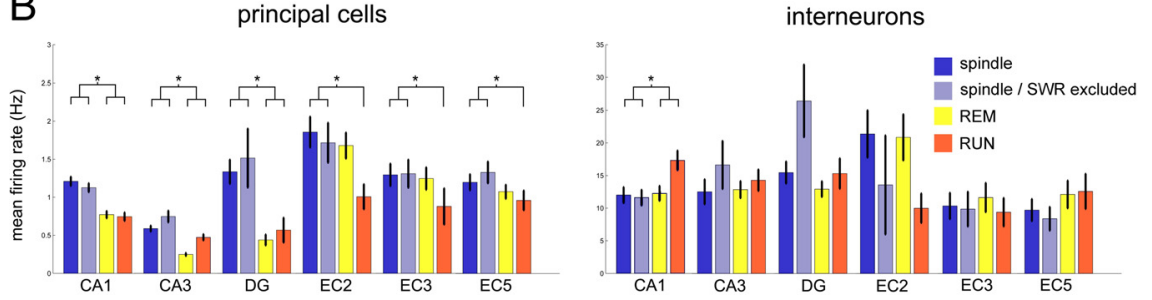

C
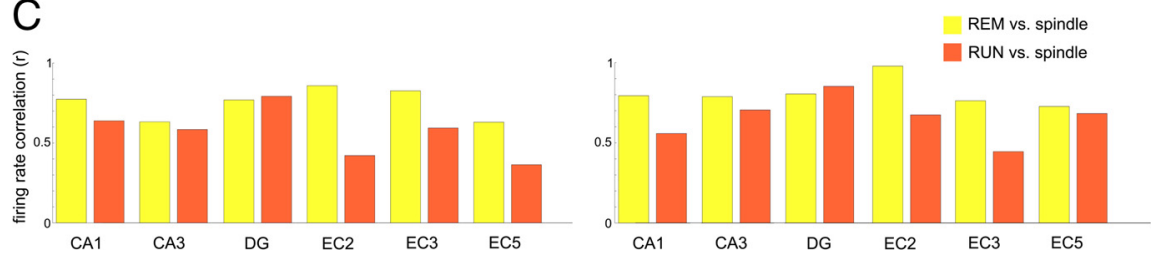

Figure 3. Firing rates are correlated across theta and spindle states. $\boldsymbol{A}$, Correlations between firing rates during REM theta and spindle events (left) and RUN theta and spindle events (right) for both principal cells and interneurons. Note the log scale on both axes and that firing rates are higher during spindles. Each dot represents a single neuron. $\boldsymbol{B}$, Mean firing rates during RUN, REM, and spindle events (with and without ripples excluded from spindle epochs) for all regions and both cell types. Significant differences are shown $(p<0.00001)$. C, Firing rate correlation coefficients between spindle and theta states in different regions. All correlations were significant $(p<0.05)$.

which the normalized signal was at least 1.4 SDs above the mean for a duration of at least $350 \mathrm{~ms}$ were selected. The trough-to-trough duration of each individual cycle was calculated for each preliminary spindle epoch, and any preliminary spindle epochs containing any cycles of duration $>125 \mathrm{~ms}$ were discarded, as were any spindles detected outside of non-REM sleep.

Coherence. For coherence analysis of spindles, we used a modified version of the multitaper FFT MATLAB package by Mitra and Pesaran (1999). Using a fixed FFT window length of $1 \mathrm{~s}$ centered on the midpoints of detected spindles, we calculated coherence over frequencies ranging from 1 to $250 \mathrm{~Hz}$ between spindles in the CA1 pyramidal layer and entorhinal layer 5.

Consecutive cycle firing index. To quantify the tendency for neurons to fire on consecutive cycles of an oscillation, we created a measure termed consecutive cycle firing index (CCF). For each neuron, CCF is calculated as the difference between two conditional expectations: (1) the theoretical expectation of the number of spikes, up to one, that a neuron will fire on a given cycle of an oscillation given that the neuron fired at least one spike on the previous cycle; and (2) the empirically observed value of this expectation. The theoretical conditional expectation assumes that neurons spike in a Poisson distributed pattern at their observed firing rate during the oscillation in question and is either the firing rate of the neuron divided by the mean frequency of the oscillation in question or one, whichever is less.

Spike phase spectrum. We attempted to identify rhythmic oscillation of single units relative to LFP by transforming spike trains into time series of theta or spindle phase and then estimating the power spectrum of these transformed spike trains via a multitaper FFT (Mizuseki et al., 2009). Our methods were the same as those used by Mizuseki et al., except that spike phase was computed via wavelet analysis (see above), and only spikes in which instantaneous firing rate (defined as firing rate in a window \pm 500 $\mathrm{ms}$ from a given spike) was $5 \mathrm{~Hz}$ were included.

\section{Results}

Sleep spindles are typically studied in the context of interactions between and/or within thalamus and neocortex, whereas the spindles examined in this study were detected in either the EC or hippocampus. The degree to which sleep spindles are synchronous across different brain regions in the rat is not known. Nir et al. (2011) reported that, in epileptic human patients implanted with multiple subdural electrodes, sleep spindles were most often synchronous across a subset of $\sim 20 \%$ of electrodes, although some spindles had a more global spread; our observations are not inconsistent with these findings. In three rats, we performed simultaneous recordings in the CA1 pyramidal layer and deep layers of the neocortex. Spindles detected in CA1 were simultaneously detected in neocortex only a minority of the time $(11.7,4.65$, and $18.1 \%$, respectively).

In support of previous studies (Sirota et al., 2003; Nir et al., 2011), we observed LFP sleep spindles in the hippocampus that occurred simultaneously with spindles recorded in the neocortex and EC (Fig. 1A,B). Although sleep spindles had a somewhat variable frequency, their modal peak was $12 \mathrm{~Hz}$ in the hippocampus (Fig. $1 C$; mean of $12.37 \mathrm{~Hz} ; n=14$ rats), EC (mean of $12.31 \mathrm{~Hz} ; n=4$ rats), and the somatosensory-visual cortex (mean of $12.39 \mathrm{~Hz} ; n=2$ rats). Sleep spindles did not have a characteristic duration. The great majority of spindle events were short $(95 \%$ under $680 \mathrm{~ms}$ ), whereas a small minority exceeded $0.8 \mathrm{~s}$ (Fig. 1D). When spindles were recorded simultaneously in the hippocampus and EC, they were strongly coherent (Fig. $1 E ;>0.7$ ). The detected spindles in the hippocampus were not simply volume conducted from the overlying neocortex because hippocampal units were also phase locked to the spindles (see below). During sleep spindles, the rate of occurrence of sharp wave ripples (SWR) was $\sim 1.8$ times greater than the baseline non-REM sleep rate of occurrence (Fig. $1 F)$. In all additional analyses, spindles recorded from the CA1 pyramidal layer were used, unless otherwise specified.

\section{CSD profiles of sleep spindles and theta oscillations in the hippocampus}

In four rats with linear probes in multiple hippocampal layers, the laminar distribution of the spindle events could be studied in detail. CSD maps showed that sleep spindles were associated with large sinks in the CA1 stratum lacunosum-moleculare and in the dentate molecular layer, with corresponding sources surrounding the sinks (Fig. 2A,B). Despite the intermittent nature and higher frequency, the within-hippocampus depth distribution of sinks and sources associated with sleep spindles were remarkably similar to CSD maps of theta oscillations during RUN and REM (Buzsáki et al., 1986; Brankack et al., 1993; Kamondi et al., 1998; Montgomery et al., 2009; Fig. 2B). These findings suggest that the synapses and afferent inputs responsible for the bulk of extracellular currents during sleep spindles are essentially the same as 

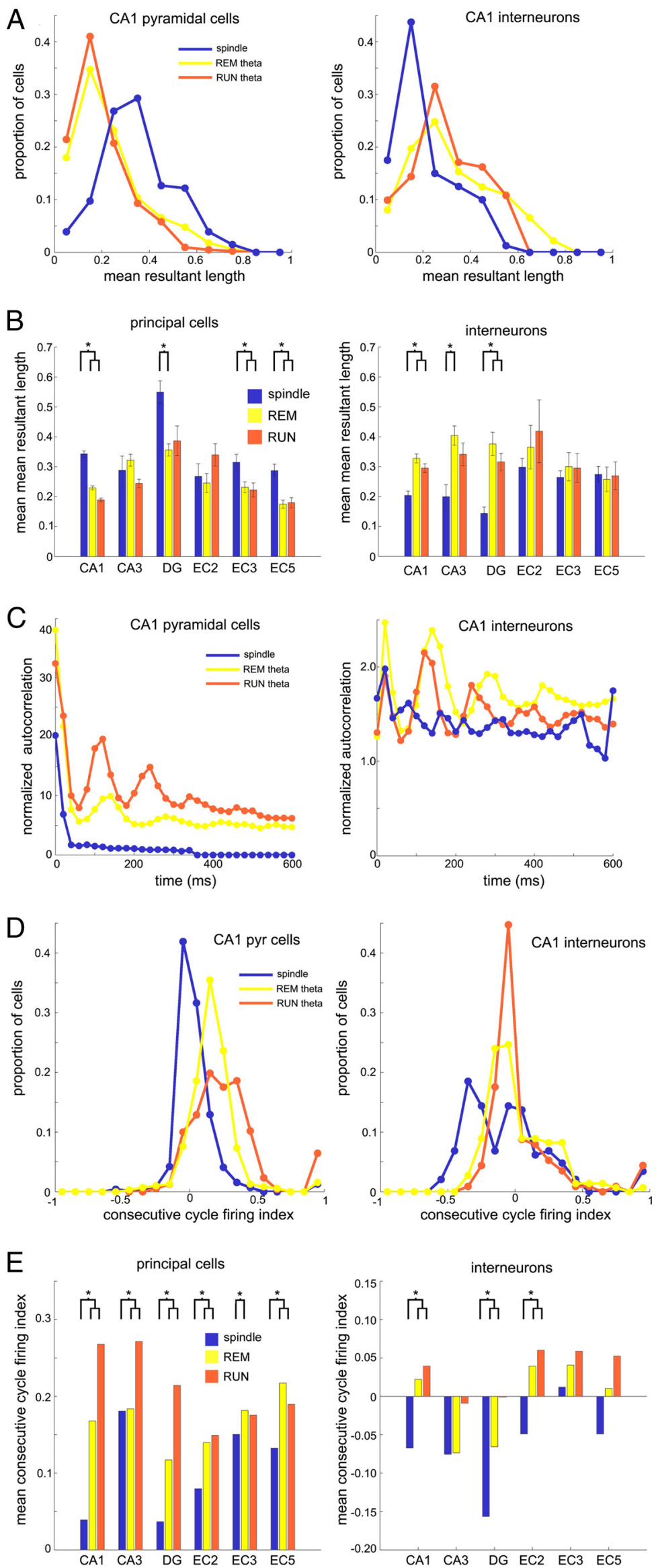

those involved in the current generation of theta oscillations, particularly the layer 2 and layer 3 afferents of the EC, perhaps complemented by the thalamic nucleus reuniens projection to the CA1 stratum lacunosum-moleculare. In contrast to the locations, the timing of the dipoles was different during spindle and theta oscillations (Fig. 2C). The current sources, recorded from the CA1, CA3 pyramidal layer, and dentate granule cell layer, showed substantial phase shifts during theta oscillations of RUN and REM, whereas during sleep spindles, they were essentially synchronous, an indication that excitation arrives virtually simultaneously from the EC to all hippocampal regions.

\section{Neuronal discharges associated with sleep spindles and theta oscillations in the hippocampus and EC}

Because brain states associated with theta oscillations and sleep spindles are different, we first examined the relationship between firing rates of neurons during these patterns. The mean firing rates of hippocampus principal cells were significantly elevated during the short bouts of sleep spindles compared with theta oscillations of REM and RUN (Fig. $3 A, B ; p<$ 0.00001, Kruskal-Wallis test). In the EC, the firing rates of principal cells during spindles were essentially similar to those of REM but significantly faster than during RUN (Fig. $3 B ; p<0.00001$ ). Because during sleep spindles the rate of occurrence of sharp wave ripples is $\sim 1.8$ times greater than the baseline non-REM sleep rate of occurrence (Siapas and Wilson, 1998; Sirota et al., 2003; Mölle et al., 2006;

Figure 4. EC- hippocampal principal cells fire sporadically but strongly phase locked during spindles. $A$, Distribution of mean resultant lengths of phase modulation for CA1 pyramidal cells and interneurons during RUN and REM theta and spindle events. $\boldsymbol{B}$, Group means of the mean resultant lengths of phase modulation in different regions. Note the stronger phase modulation of principal cells and weaker modulation of interneurons during spindles in many regions. Significant differences $(p<0.05)$ are indicated by ${ }^{*}$. C, Normalized autocorrelograms of CA1 pyramidal cells and interneurons. Note autorhythmicity during both RUN and REM and lack of rhythmic firing during spindle. $D$, Distribution of CCF of CA1 pyramidal cells and interneurons. Positive numbers indicate that the unit fires on consecutive cycles of the given rhythm more often than predicted by the firing rate of the unit alone. Note the primarily symmetric distribution during spindles for pyramidal cells and negative shift for interneurons attributable to cycle skipping higher than chance. $\boldsymbol{E}$, Group means of the CCF in each region. Note the values close to 0 for principal cells and negative values for interneurons during spindles. Significant differences $(p<0.01)$ are indicated by * 

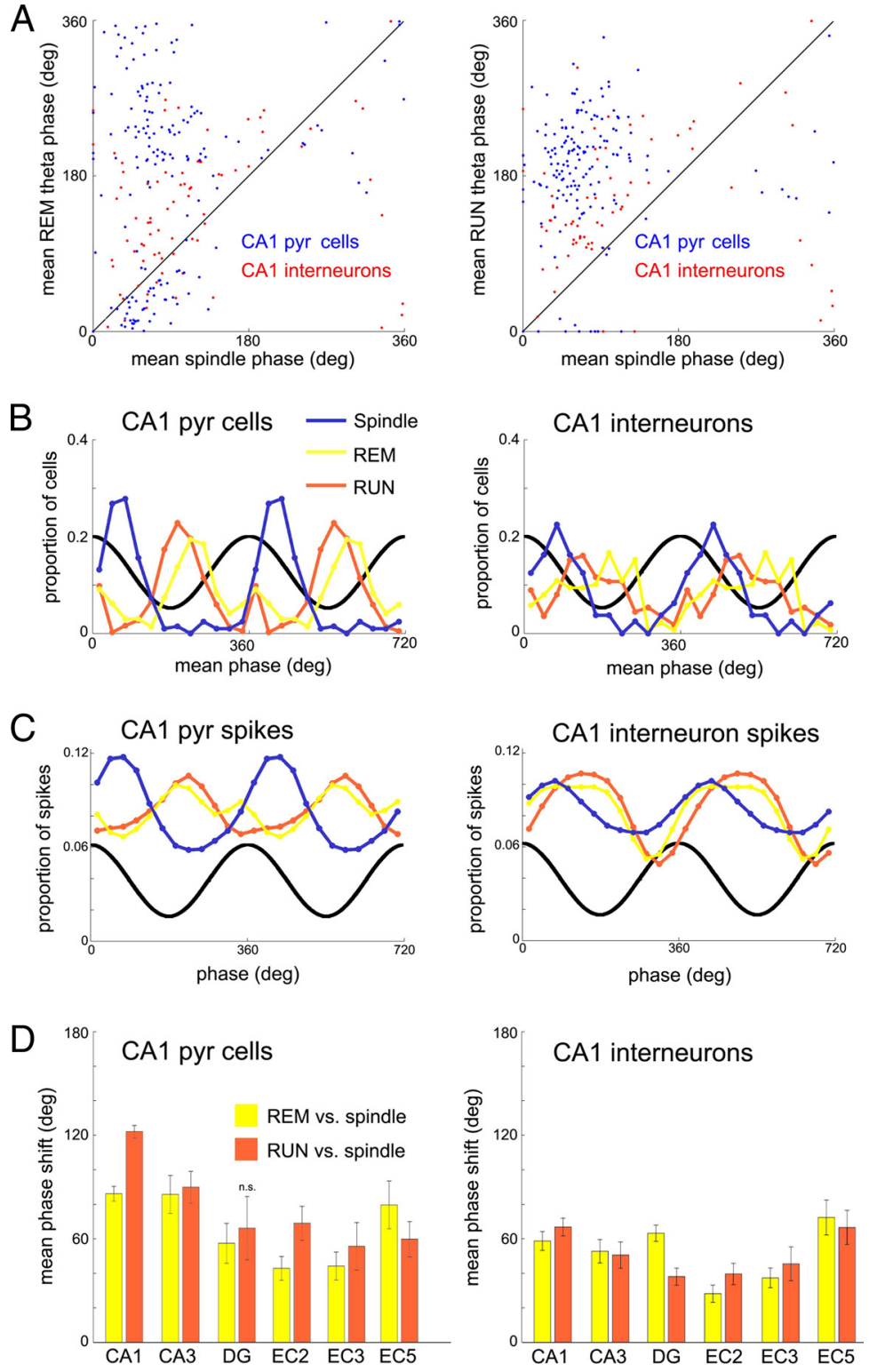

Figure 5. Firing phase preferences are different during theta and spindles. $A$, Correlations between phase preferences of $C A 1$ pyramidal cells and interneurons between REM theta and spindle events (left) and RUN theta and spindle events (right). Each dot is a single neuron with significant phase locking to both theta and spindles. $\boldsymbol{B}$, Distribution of phase preferences of significantly phase-modulated CA1 pyramidal cells (left) and interneurons (right). Black sinusoid represents CA1 pyramidal layer LFP. C, Phase distribution of spikes of all CA1 pyramidal cells (left) and interneurons (right). All neurons are included, independent of whether they were significantly phase locked to the LFP rhythm. $D$, Mean and SEM phase shift of the preferred firing phase between REM theta and spindle events and RUN theta and spindle events. All comparisons are significant $(p<0.0005)$ except for DG granule cells between spindle and RUN.

Peyrache et al., 2011; Phillips et al., 2012; Fig. 1 F), we reexamined the firing rate relationships between spindles and theta after removing portions of spindle episodes associated with ripples from the analysis (here, $32 \%$ of spindles detected in the CA1 pyramidal layer contained at least one ripple). Removing ripple epochs from identified spindles did not affect the quantitative differences in firing rates between spindles and theta during RUN or REM (Fig. $3 B)$. Firing rates during spindles with and without ripple epochs removed were not significantly different from each other. The mean firing rates of interneurons did not significantly differ between spindles and either REM or RUN theta, except those of CA1 interneurons, which fired faster during RUN theta than during spindles (Fig. $3 B ; p<0.05$ ).
Despite the firing rate differences across states, a strong, significant firing rate correlation was observed between spindles and REM/RUN for all neurons types and regions (Fig. $3 A, C ; p<0.05$ ). The firing rate correlations generally were higher between spindles and REM (range, 0.65-0.95) than between spindles and RUN (range, 0.40-0.85).

\section{Phase modulation of spikes during sleep spindles and theta oscillations}

The next analysis examined the relationship between unit firing and LFP. A considerable fraction of both principal cells (CA1, 205 of 711; CA3, 42 of 370; DG, 13 of 71; EC2, 26 of 82; EC3, 18 of 106; EC5, 21 of 148) and interneurons (CA1, 80 of 146; CA3, 29 of 69; DG, 45 of 68; EC2, 14 of 27; EC3, 21 of 42; EC5, 22 of 34) was significantly $(p<0.05$, Hodges-Ajne test) phase locked to sleep spindles. However, these fractions were lower than those modulated by theta oscillations of RUN (pyramidal cells: CA1, 438 of 572; CA3, 268 of 357; DG, 28 of 35; EC2, 70 of 82; EC3, 70 of 106; EC5, 81 of 148; interneurons: CA1, 112 of 116; CA3, 57 of 59; DG, 31 of 33; EC2, 27 of 27; EC3, 33 of 42; EC5, 30 of 34 ) or REM (pyramidal cells: CA1, 504 of 711; CA3, 240 of 370; DG, 50 of 71; EC2, 80 of 82; EC3, 80 of 106; EC5, 91 of 148; interneurons: CA1, 138 of 146; CA3, 65 of 69; DG, 68 of 68; EC2, 25 of 27; EC3, 36 of 42; EC5, 32 of 34). One explanation for the lower percentage of significantly modulated neurons during sleep spindles is that, because of the short duration of spindles, lower numbers of spikes were available for the analysis compared with the long trains of theta waves during REM and RUN. To address this issue quantitatively, the REM theta epochs were truncated so that the duration of REM analyzed in a given session was equal to the duration of spindles. As expected, the downsampling process reduced the number of significantly theta phase-locked neurons during REM by $12-35 \%$ (pyramidal cells: CA1, 332 of 711; CA3, 210 of 370; DG, 35 of 71; EC2, 51 of 82; EC3, 49 of 106; EC5, 61 of 148; interneurons: CA1, 113 of 146; CA3, 55 of 69; DG, 58 of 68; EC2, 21 of 27; EC3, 30 of 42; EC5, 23 of 34). However, these fractions are still higher than for sleep spindles in any region. Thus, despite the overall higher firing rates of hippocampal principal cells during spindles, a smaller fraction of them was significantly phase modulated compared with REM.

Unexpectedly, the mean resultant length ("modulation index") of principal cells was significantly higher during sleep spindles compared with theta for the significantly spindle-modulated neurons (Fig. $4 A, B ; p<0.05$, except CA3 and EC2 regions), demonstrating a stronger phase locking of spikes to spindles of a minority of neurons compared with theta oscillations. Interest- 

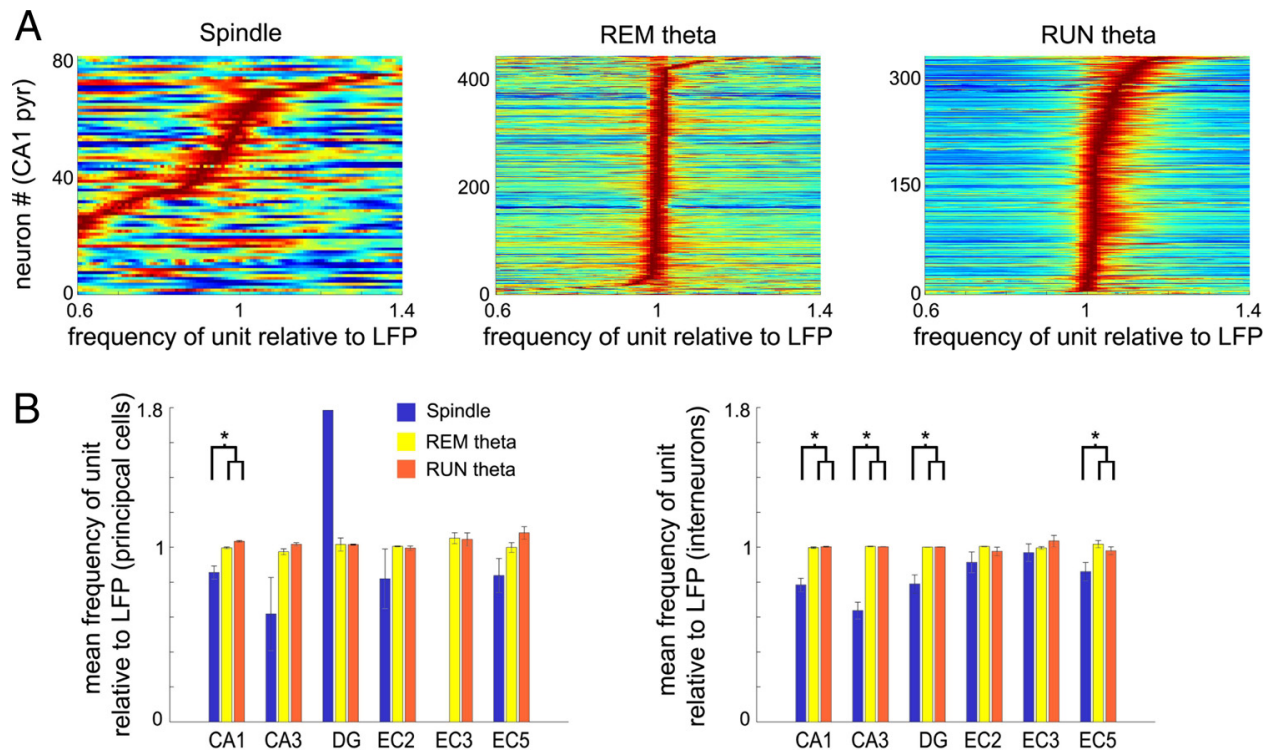

Figure 6. Phase interference of principal cells during theta and spindle oscillations. A, Spike phase spectra of neurons (Mizuseki et al., 2009; see Materials and Methods). Each color-coded row represents the power spectrum of a single CA1 pyramidal neuron, sorted by the magnitude of frequency shift of the power spectral peak. Power spectra were normalized by the amplitude of their peaks. Positive values indicate phase precession (0'Keefe and Recce, 1993). Note phase precession of many neurons during RUN and mainly phase retardation during spindle. $\boldsymbol{B}$, Mean phase interference index (i.e., abscissa of $A$ ) for principal cells and interneurons in different regions. Significant differences $(p<0.05)$ are indicated by *. Only one $D G$ principal cell had a valid spike phase spectrum during spindle events.

ingly, an opposite relationship was dominant for interneurons, because they were less strongly phase locked to spindle than to theta oscillations, although this difference reached significance only in the hippocampal regions (Fig. 4A,B). Commensurate with the phase-locking results, the spike autocorrelograms of both principal cells and interneurons showed multiple rhythmic peaks in the theta band during REM and RUN (Fig. 4C). In contrast, secondary peaks were conspicuously absent during sleep spindles for both principal cells and interneurons (Fig. 4C). In the EC, a few units had rhythmic peaks at $\sim 5 \mathrm{~Hz}$ in their autocorrelograms, but only few of these were significantly phase modulated by sleep spindles (data not shown).

The lack of rhythmicity in the autocorrelograms during spindles, despite strong phase modulation of unit activity, implies that neurons did not reliably fire trains of spikes on consecutive spindle cycles. To quantify this relationship, we introduced a CCF (see Materials and Methods). Positive CCF indicates that the unit fires on consecutive cycles of the given rhythm more often than predicted by the firing rate of the unit alone, zero CCF indicates that the unit fires on consecutive cycles as predicted from firing rate, and negative CCF indicates that the unit fires on consecutive cycles less than predicted by firing rate. Figure $4 D$ shows the distribution of CCF for CA1 pyramidal cells and interneurons in spindles, RUN theta, and REM theta; note that CCF distributions for either theta are shifted to the right compared with spindles. For principal cells in all regions, CCF was significantly higher for REM and RUN theta than for spindles (Fig. 4E; $p<0.0001$, Kruskal-Wallis test). Only interneurons in CA1, DG, and EC2 showed significant differences in CCF, with lower CCF for spindles than theta ( $p<0.01$, Kruskal-Wallis test). The irregular participation of neurons in successive spindle cycles is further supported by the Fano factor (variance of the number of spikes in a spindle cycle divided by the mean). The median Fano factor was significantly lower for CA1 pyramidal cells during spindles $(F=$ $1.73)$ than during either REM $(F=2.06)$ or RUN $(F=2.11)(p<$ 0.00001 , Kruskal-Wallis test). This was true for all principal cells in both hippocampus and EC $(p<0.00001$, except DG where $p=$ 0.06 ) but not for interneurons (except DG but only for REM theta; $p<0.05$ ).

In contrast to the high correlation of firing rates across states in all layers, the spindle versus theta phase relationship of the hippocampal and entorhinal neurons showed important regional differences. For determining the shift of phase preference from theta to spindle, only neurons that passed the Hodges-Ajne test for non-uniformity of circular data $(p<0.05)$ for both REM theta and spindles were included. CA1 principal cells showed a large and significant phase advancement of their preferred spiking during spindles relative to theta during REM and RUN (Fig. $5 A, B, D$; REM vs spindle, $86.11 \pm 55.18^{\circ}, p<0.00001$; RUN vs spindle, $122.10 \pm 44.90^{\circ}, p<0.00001$, Wilcoxon's signed-rank test). Whereas individual CA1 neurons showed a wide range of theta phase preference (Fig. $5 A$ ), they had a more uniform phaselocking preference to the descending part of the spindle cycle $\left(64.14 \pm 42.85^{\circ}\right)$, i.e., following the sink maximum in stratum lacunosum-moleculare (Fig. 2). Although the magnitude of phase shift of both principal cells and interneurons between spindle and theta oscillations was generally less in other regions, they were nevertheless significant (Fig. 5D; $p<0.0005$, all regions/cell types/theta types except DG granule cell layer for RUN theta, attributable to low $n$ ). Another method to examine the phase relationship of spikes and LFP is to generate histograms illustrating the relationship between theta/spindle phase and spiking, independent of whether individual neurons are significantly phase locked to the LFP or not. The theta phase histograms constructed this way showed phase shifts comparable with the phase preference histograms (Fig. 5C).

Another quantitative method for the comparison between unit firing and LFP is the "phase precession index." Hippocampal and EC2 principal cells show a systematic backward phase shift from late to early phases of theta as the rat traverses the place field or "grid" apexes (O'Keefe and Recce, 1993; Hafting et al., 2008). The phase precession is an indication that the neuron oscillates 
A
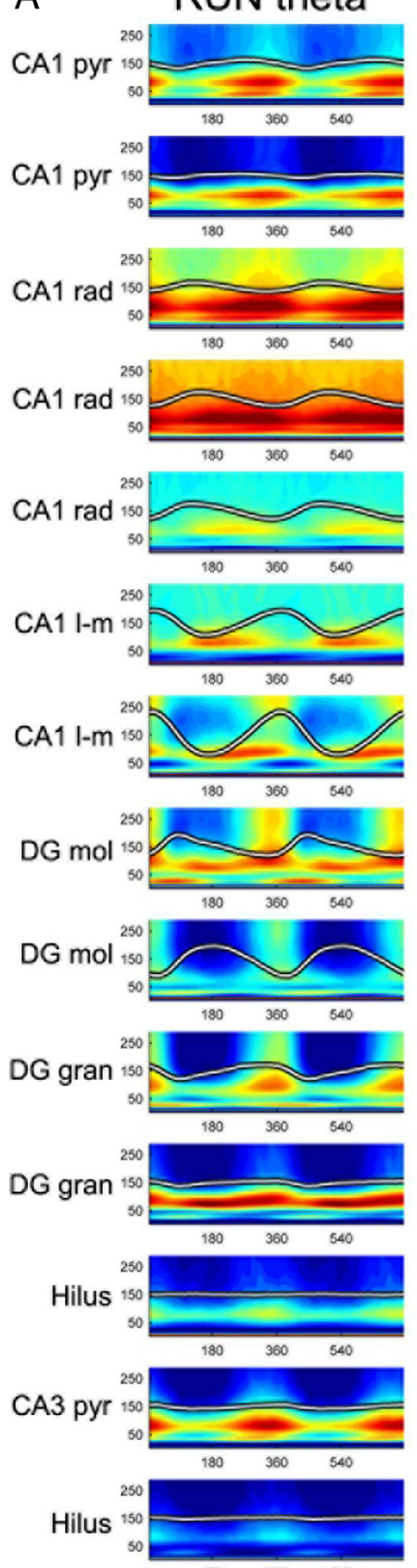
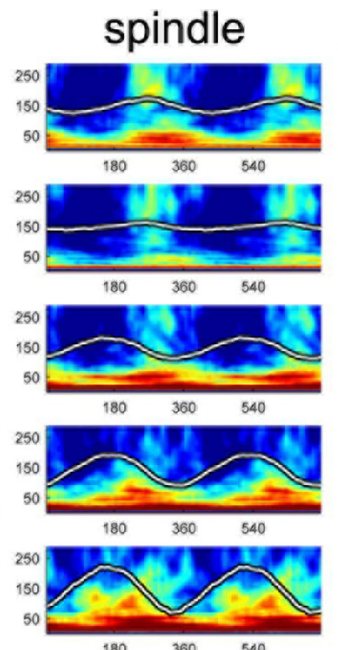

$\begin{array}{lll}180 & 360 & 540\end{array}$

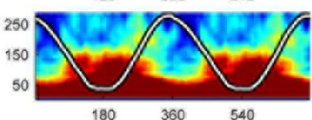

$\begin{array}{lll}180 & 360 & 540\end{array}$
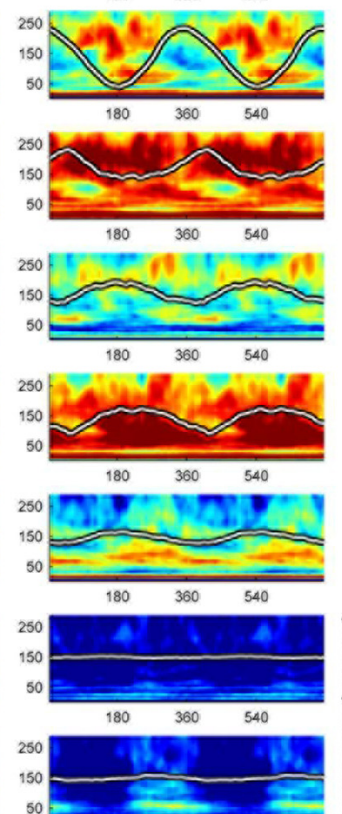

.

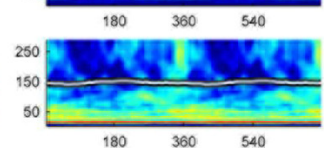

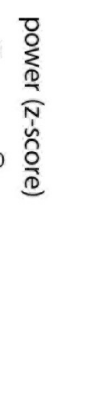
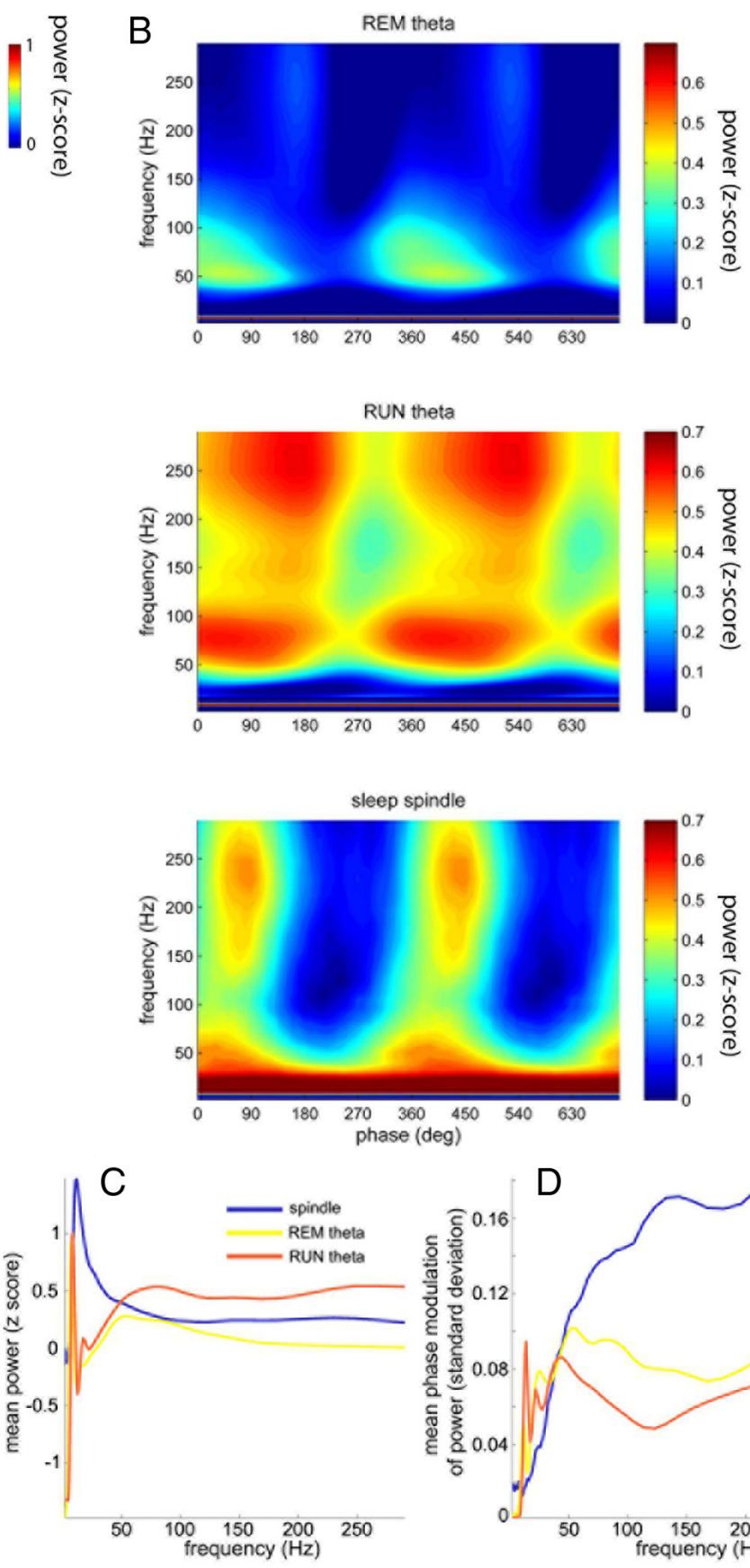

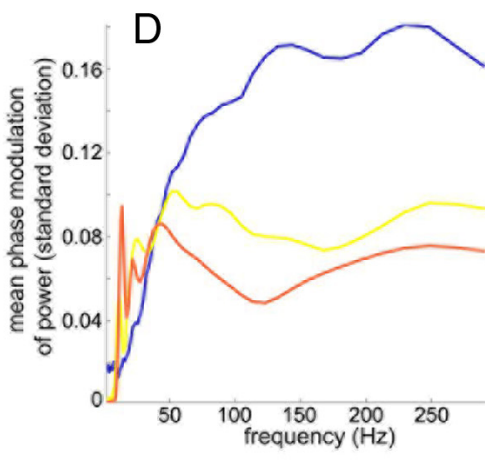

Figure 7. Cross-frequency phase-amplitude coupling during theta and spindle oscillations. $\boldsymbol{A}$, Phase-modulated CSD wavelet maps during theta (RUN) and spindle activity at different depths. The color axis plots mean normalized power as a function of phase (determined from the deepest CA1 I-m channel) and frequency; power data from each channel is individually $Z$-score normalized. Single-session CSD traces of simultaneously recorded sites (as in Fig. $2 A$ ) are superimposed on the wavelet maps. Of all hippocampal layers, gamma power is largest in the hilar region. $\boldsymbol{B}$, Mean LFP wavelet maps from the CA1 pyramidal layer averaged over multiple animals ( $n=23$ sessions in 14 rats for REM and spindle; $n=17$ sessions in 10 rats for RUN theta). Note the dominance of gamma power in the $50-90 \mathrm{~Hz}$ band during theta and its lack during spindle events. C, Group mean power spectra for RUN, REM, and spindle events. $D$, Theta and spindle phase modulation of spectral power (SD of power across phase as a function of frequency). CA1 pyr, Pyramidal layer; CA1 rad, stratum radiatum; CA1 I-m, stratum lacunosum-moleculare; DG mol, dentate gyrus molecular layer; DG gran, granule cell layer; CA3 pyr, pyramidal layer in the hilar region.

faster than the reference LFP theta (O'Keefe and Recce, 1993; Maurer et al., 2006; Geisler et al., 2007; Jeewajee et al., 2008), and this phase difference can be expressed in the "spike phase spectrum" (Mizuseki et al., 2009). Figure 6A illustrates the phase precession index for CA1 pyramidal cells. Many neurons showed spike phase precession during RUN, as indicated by the $>1$ index. Although hippocampal cells can show phase precession also during REM when individual spike trains are considered (Harris et al., 2002), for most neurons, the value was near 1. As expected from the CCF, only a minority of CA1 pyramidal cells had a spike spectrum index near 1 or $>1$ during spindles. Instead, a considerable fraction had values $<1$, indicating that CA1 pyramidal neurons oscillated at a frequency below the spindle band. This pattern of firing, in general, also applied to principal cells and interneurons of other regions and layers (Fig. 6B). Overall, these results show that principal cells of the hippocampus and EC tend to fire in clusters during theta oscillations of RUN and REM with a high probability of spikes on consecutive theta cycles. In con- 
trast, they fire sporadically during sleep spindles, although the emitted spikes tend to be strongly phase locked to a restricted phase range of the spindle.

\section{Cross-frequency modulation of LFP gamma power by sleep spindles} Because recent studies have described spindle phase modulation of gamma power in the neocortex (Peyrache et al., 2011; Ayoub et al., 2012), we examined spindle phase locking of higher-frequency activity in the hippocampus. As reported previously, theta oscillations strongly entrained gamma band $(30-90 \mathrm{~Hz})$ and epsilon band (>90 Hz; Freeman, 2007) activity during RUN (Bragin et al., 1995; Chrobak and Buzsáki, 1998; Csicsvari et al., 2003; Canolty et al., 2006; Colgin et al., 2009; Belluscio et al., 2012; Buzsáki and Wang, 2012; Fig. 77). Whereas LFP gamma amplitude during theta oscillations is largest in the hilar region and CA1 stratum radiatum (Csicsvari et al., 2003), the strongest modulation of gamma band activity during spindles was observed in CA1 stratum lacunosum-moleculare and the dentate gyrus (Fig. 7A). Group comparison from the CA1 pyramidal layer (spindle and REM theta, $n=23$ sessions in 14 rats; RUN theta, $n=17$ sessions in 10 rats) revealed differences in thetagamma band coupling (Fig. $7 B, C$ ). During RUN and REM, the dominant gamma activity in the CA1 pyramidal layer occurred in the $40-100 \mathrm{~Hz}$ band on the descending phase of the theta waves, with additional phase modulation of the epsilon band. During sleep spindles, the epsilon band also showed strong phase modulation, but the dominant gamma band activity was confined to frequencies $<50 \mathrm{~Hz}$ (Fig. 7C). The oscillatory nature of this lower band is questionable, because within the half-wave of a spindle $(\sim 40$ $\mathrm{ms}$ ), not even two cycles of slow gamma events could fit. The epsilon band, especially $100 \mathrm{~Hz}$, may primarily reflect spiking activity during both theta (Belluscio et al., 2012) and spindle oscillations, because spike and epsilon band modulation shared the same phase range. Frequency bands in which spectral power in the CA1 pyramidal layer is modulated by the phase of spindles and theta are illustrated in Figure $7 D$, in which the SD of wavelet power over the $3610^{\circ}$ phase bins is plotted as a function of frequency. For REM theta, the initial two peaks in Figure $7 D$ indicate phase modulation of harmonics at 12 and $25 \mathrm{~Hz}$; subsequent peaks indicate phase modulation of gamma bands centered at 52 and $80 \mathrm{~Hz}$ and the epilson band at $250 \mathrm{~Hz}$. For RUN theta, the initial two peaks indicate phase modulation of harmonics at 14 and $22 \mathrm{~Hz}$; subsequent peaks indicate phase modulation of a gamma band $\sim 45 \mathrm{~Hz}$ and the epsilon band at $250 \mathrm{~Hz}$. Modulation of power in CA1 by spindle phase shows a different profile, with no clear peaks in the gamma range but three minor peaks in the epsilon band, suggesting spindle phase modulation of epsilon band $(>100 \mathrm{~Hz})$, ripple $(\sim 150 \mathrm{~Hz})$, and unit $(\sim 250 \mathrm{~Hz})$ activity (ripple epochs were excluded from this analysis, but a minority of ripples might have escaped our detection method).

\section{Spindle recruitment of the hippocampal-EC system during intermediate sleep}

The different frequencies of LFP sleep spindles and unit firing patterns suggested that the neocortical inputs and intrahippocampal oscillatory patterns can transiently couple and uncouple. This may be particularly eminent during the short intermediate sleep episodes when the neocortex is still in non-REM sleep and the hippocampus switches to theta bouts (Gottesmann, 1973). We defined REM sleep onset by using the power ratio in theta (5-11 Hz) and delta (1-4 Hz) bands (see Materials and Methods; Mizuseki et al., 2009; Grosmark et al., 2012). Non-REM-REM transitions coincided with a large reduction of sharp wave ripples, increased and decreased discharge of putative interneurons and pyramidal cells, respectively (Fig. 8; Grosmark et al., 2012). In agreement with previous observations (Gottesmann, 1973), REM 

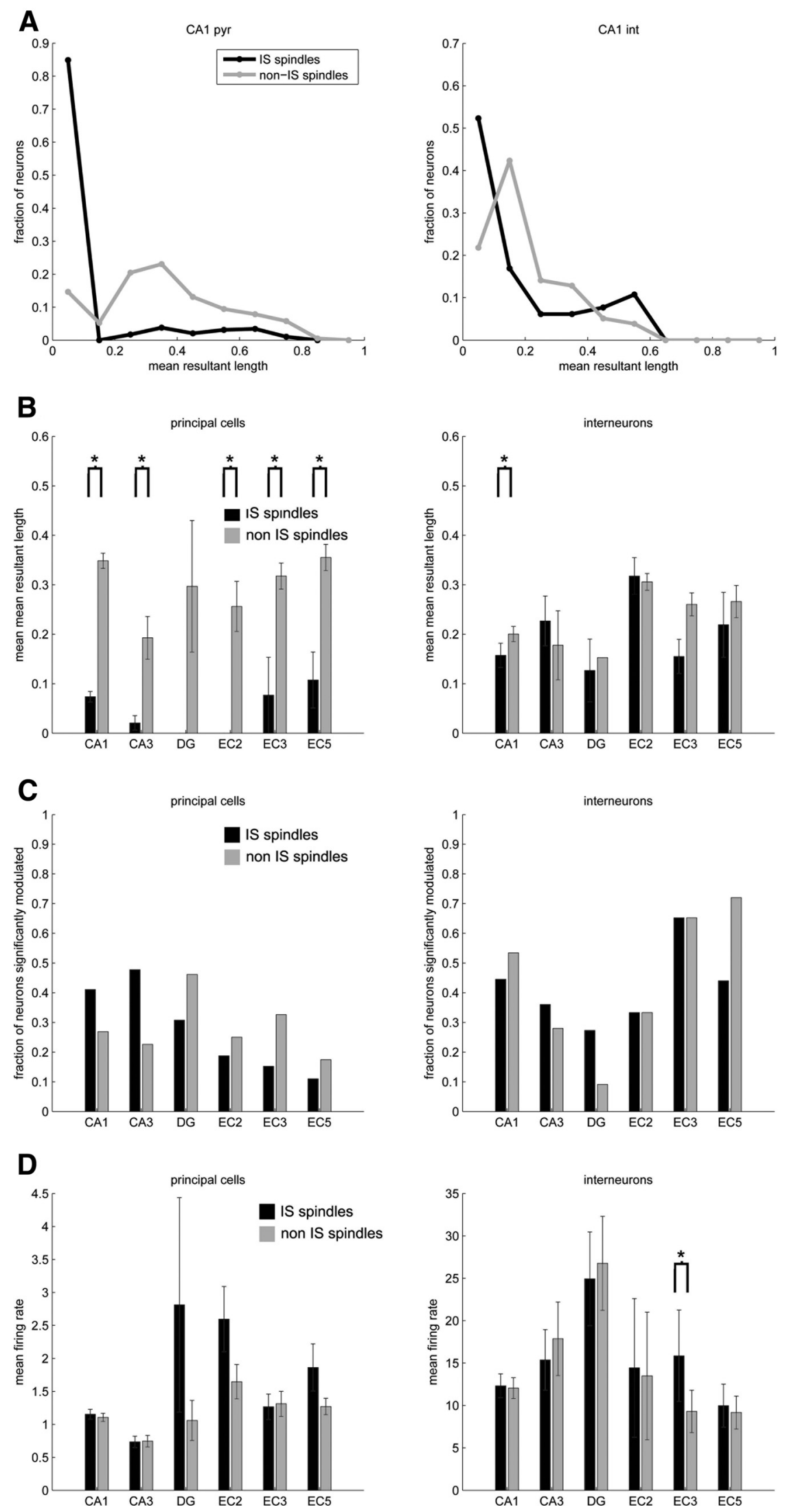

Figure 9. Entrainment of EC- hippocampal circuits by sleep spindles during non-REM and intermediate sleep. $A$, Distribution of the mean resultant lengths (phase modulation) of CA1 pyramidal cells and interneurons during spindles detected during intermediate sleep (IS spindles) and non-REM sleep (non-IS spindles). $\boldsymbol{B}$, Average values (and SEM) or the mean resultant length during IS and non-IS spindles. ${ }^{*} p<0.05$. C, Fraction of significantly modulated neurons during IS and non-IS spindles. D. Firing rates of neurons during IS and non-IS spindle events. sleep was preceded by a surge of sleep spindles, peaking $10-15 \mathrm{~s}$ before the onset of hippocampal theta oscillations (Fig. 8). In this transitional state, hippocampal activity rapidly and smoothly shifted back and forth between $6-8 \mathrm{~Hz}$ theta and spindle frequency oscillations.

Given the special status of sleep spindles in intermediate sleep, we reexamined the firing pattern relationship of neurons with spindles that occurred during intermediate sleep (defined as the $20 \mathrm{~s}$ period before REM onset) and non-REM sleep. Spindle wave modulation of principal cells (i.e., the mean resultant length) was significantly stronger during spindles that occurred during non-REM than intermediate sleep in all regions and layers $(p<$ 0.05 , Kruskal-Wallis test). In the interneuron groups, only the firing rate of CA1 interneurons was significantly different between spindles of non-REM and intermediate sleep (Fig. 9A,B). The fraction of significantly phase-modulated neurons were higher in the CA1 and CA3 regions but lower in other regions during spindles of intermediate sleep (Fig. 9C). The firing rates of principal cells and interneurons were similar during the two types of spindles in all regions except for putative interneurons in entorhinal layer 3 (Fig. 9D).

\section{Discussion}

Our findings show that, although EC afferents to the hippocampus are involved in the establishment of current generators of both theta oscillations and sleep spindles, the temporal coordination of both the sink sources of the extracellular currents and unit firing patterns in the EC and hippocampus are quite different. During waking, the entire phase range of theta oscillations is used by cell assembly sequences, whereas hippocampal neurons participating in successive waves of sleep spindles are much less organized. Most principal cells fire relatively synchronously in all hippocampal regions compared with the time-shifted patterns during theta oscillations.

\section{Neocortical-EC-hippocampal propagation of activity during sleep}

At least two major patterns can convey neocortical information to the entorhinal-hippocampus system during nonREM sleep: (1) slow oscillations (Steriade et al., 1993a,b); and (2) the associated sleep spindles (Sirota et al., 2003; Isomura et al., 2006; Mölle et al., 2006; Wolansky et al., 2006; Hahn et al., 2007; Nir et al., 2011; Logothetis et al., 2012). A large part of this neuronal traffic takes place during sleep 
spindles (Siapas and Wilson, 1998; Sirota et al., 2003; Eschenko et al., 2006; Isomura et al., 2006; Mölle et al., 2006; Clemens et al., 2007, 2010; Nishida and Walker, 2007; Johnson et al., 2010; Peyrache et al., 2011; Sullivan et al., 2011). Our laminar analyses of the different hippocampal layers and regions showed that the main excitatory dipoles responsible for the excitation of the hippocampal circuits during sleep spindles reside in the CA1 stratum lacunosum-moleculare and the dentate molecular layer (Fig. 2). Importantly, these same two direct EC pathways, originating from layers III and II, respectively, are also responsible for the largest extracellular currents underlying intrahippocampal theta waves (Buzsáki et al., 1986; Brankack et al., 1993). Indeed, the locations of the sinks and sources of both theta and spindle waves were remarkably similar. However, important differences were also noted. The most important difference was in the timing of the dipoles. During theta oscillations, the sinks in CA1 stratum lacunosum-moleculare and the dentate molecular layer were approximately antiphase, commensurate with the primarily antiphase firing of layer II and layer III principal cells (Mizuseki et al., 2009). In contrast, the sinks in these respective layers were primarily synchronous during spindles, in congruence with the inphase firing of all EC and hippocampal principal neurons.

\section{Distinct neuronal firing patterns during spindles and theta rhythms}

In the absence of theta oscillations, four major network patterns can sustain neuronal spiking in the hippocampus-EC. Among these, sharp wave ripples and gamma-epsilon band oscillation bouts are self-generated and originate in the CA3 system (Buzsáki et al., 1992; Csicsvari et al., 2003; Sullivan et al., 2011). These intrinsic patterns, particularly ripples, give rise to highly organized sequences of neurons primarily reflecting cell assembly sequences in the previous waking periods (Wilson and McNaughton, 1994). The remaining two patterns are extrinsic, including slow oscillations (Steriade et al., 1993a) and spindle oscillations. Both extrinsic patterns can drive firing in the EChippocampus circuits and interact with the intrinsic sharp wave ripples and gamma oscillations (Sirota et al., 2003; Isomura et al., 2006; Mölle et al., 2006; Wolansky et al., 2006; Nir et al., 2011).

There are at least two possible consequences of the neocortically mediated effects on hippocampal circuits. First, they can provide a random selection of EC-hippocampal neurons. Generating random recruitment of hippocampal neurons could be straightforward if a relatively random constellation of neocortical neurons participates in successive sleep spindle waves and spindle events. Such a mechanism could serve to equalize or "homogenize" synaptic weights and reduce the excitability across systems that has increased in the waking state (Tononi and Cirelli, 2006). A second possibility is that sleep spindles give rise to consistent and highly organized spike trains in the neocortex, which in turn could effectively bias not only the time of occurrence but also the neuronal spike content of entorhinal-hippocampal neurons. There is reason to believe that sleep spindles are indeed critical for temporally coordinated neocortical neurons in at least some areas because Johnson et al. (2010) have shown that previously learned neuron spiking sequences in the prefrontal cortex reoccurred mainly during sleep spindles and that the strength of reactivation was correlated with the density of spindles. Against this background, one might expect that the orderly activation of neocortical neurons during spindles would give rise to orderly sequences in EC-hippocampal circuits as well. However, we could not detect reliably repeating patterns. Four different methods, spike autocorrelograms, phase precession, CCF, and the Fano factor, demonstrated the lack of sustained spike trains of single neurons within spindles. The implication of these observations is that, in each successive waves of the spindle, primarily different sets of principal cells participate. This firing pattern is fundamentally different from theta-related spiking activity. In the waking rat, pyramidal cells fire in multiple theta cycles in their place fields with a precise temporal relationship relative to other overlapping place neurons (O'Keefe and Recce, 1993). Similarly, neurons during REM sleep pyramidal cells fire clusters of spikes lasting for $\sim 1 \mathrm{~s}$, reminiscent of the firing patterns in the waking state (Louie and Wilson, 2001). An important role of theta oscillations is to compress representations of the sequentially active neurons into theta timescale, thus using the entire phase space of the cycle (Dragoi and Buzsáki, 2006). Both the cluster firing patterns and the phase space utilization features, characteristic of theta oscillations, are absent during sleep spindles. Instead, neurons fired in a relatively random manner in successive cycles and fired strongly in synchrony, occupying only a small phase range of the spindle waves. The synchronous discharge of EC neurons may explain why the firing rates of hippocampal principal cells are higher during spindles than during theta.

It should be emphasized that, although our observations do not demonstrate a simple cycle-to-cycle firing of neurons or their within-cycle temporal segregation, we cannot exclude the possibility of a more complex relationship among the activated EC or hippocampal neurons. The lack of orderly firing during spindles is in contrast with the striking sequential firing of neurons during sharp wave ripples (Wilson and McNaughton, 1994; Nadasdy et al., 1999). Thus, it appears that, although spindles can affect the timing of occurrence of ripples (Sirota et al., 2003; Peyrache et al., 2011), they do not "select" which hippocampal neurons participate in ripples. Despite this, it remains a possibility that spindlerelated firing in the hippocampus can serve to mix previous waking-related activity with old and stored information. In this framework, spindles could assist in blending recently acquired information into the existing knowledge base (Wagner et al., 2010). Additional studies, involving a large number of simultaneously recorded cell assemblies from neocortex and hippocampus, are needed to address these possibilities (Ji and Wilson, 2007).

\section{References}

Alonso A, Llinás RR (1989) Subthreshold $\mathrm{Na}^{+}$-dependent rhythmicity in stellate cells of entorhinal cortex layer II. Nature 342:175-177. CrossRef Medline

Astori S, Wimmer RD, Prosser HM, Corti C, Corsi M, Liaudet N, Volterra A, Franken P, Adelman JP, Lüthi A (2011) The ca(V)3.3 calcium channel is the major sleep spindle pacemaker in the thalamus. Proc Natl Acad Sci U S A 108:13823-13828. CrossRef Medline

Ayoub A, Mölle M, Preissl H, Born J (2012) Grouping of MEG gamma oscillations by EEG sleep spindles. Neuroimage 59:1491-1500. CrossRef Medline

Belluscio MA, Mizuseki K, Schmidt R, Kempter R, Buzsáki G (2012) Crossfrequency phase-phase coupling between $\theta$ and $\gamma$ oscillations in the hippocampus. J Neurosci 32:423-435. CrossRef Medline

Bragin A, Jandó G, Nádasdy Z, Hetke J, Wise K, Buzsáki G (1995) Gamma $(40-100 \mathrm{~Hz})$ oscillation in the hippocampus of the behaving rat. J Neurosci 15:47-60. Medline

Bragin A, Jandó G, Nádasdy Z, van Landeghem M, Buzsáki G (1995) Dentate EEG spikes and associated population bursts in the hippocampal hilar region of the rat. J Neurophysiol 73:1691-1705. Medline

Brankack J, Stewart M, Fox SE (1993) Current source density analysis of the hippocampal theta rhythm: associated sustained potentials and candidate synaptic generators. Brain Res 615:310-327. CrossRef Medline

Buzsáki G, Wang XJ (2012) Mechanisms of gamma oscillations. Annu Rev Neurosci 35:203-225. CrossRef Medline 
Buzsáki G, Leung LW, Vanderwolf CH (1983) Cellular bases of hippocampal EEG in the behaving rat. Brain Res 287:139-171. Medline

Buzsáki G, Czopf J, Kondákor I, Kellényi L (1986) Laminar distribution of hippocampal rhythmic slow activity (RSA) in the behaving rat: currentsrouce density analysis, effects of urethane and atropine. Brain Res 365: 125-137. CrossRef Medline

Buzsáki G, Horváth Z, Urioste R, Hetke J, Wise K (1992) High-frequency network oscillation in the hippocampus. Science 256:1025-1027. CrossRef Medline

Canolty RT, Edwards E, Dalal SS, Soltani M, Nagarajan SS, Kirsch HE, Berger MS, Barbaro NM, Knight RT (2006) High gamma power is phaselocked to theta oscillations in human neocortex. Science 313:1626-1628. CrossRef Medline

Chrobak JJ, Buzsáki G (1998) Gamma oscillations in the entorhinal cortex of the freely behaving rat. J Neurosci 18:388-398. Medline

Clemens Z, Mölle M, Eross L, Barsi P, Halász P, Born J (2007) Temporal coupling of parahippocampal ripples, sleep spindles and slow oscillations in humans. Brain 130:2868-2878. CrossRef Medline

Clemens Z, Mölle M, Eross L, Jakus R, Rasonyi G, Halasz P, Born J (2010) Finetuned coupling between human parahippocampal ripples and sleep spindles. Eur J Neurosci 33:511-520. doi: 10.1111/j.1460-9568.2010.07505.x. Medline

Colgin LL, Denninger T, Fyhn M, Hafting T, Bonnevie T, Jensen O, Moser MB, Moser EI (2009) Frequency of gamma oscillations routes flow of information in the hippocampus. Nature 462:353-357. CrossRef Medline

Contreras D, Destexhe A, Sejnowski TJ, Steriade M (1996) Control of spatiotemporal coherence of a thalamic oscillation by corticothalamic feedback. Science 274:771-774. CrossRef Medline

Csicsvari J, Hirase H, Mamiya A, Buzsáki G (2000) Ensemble patterns of hippocampal CA3-CA1 neurons during sharp wave-associated population events, Neuron 28:585-594. CrossRef

Csicsvari J, Jamieson B, Wise KD, Buzsáki G (2003) Mechanisms of gamma oscillations in the hippocampus of the behaving rat. Neuron 37:311-322. CrossRef Medline

De Gennaro L, Ferrara M (2003) Sleep spindles: an overview. Sleep Med Rev 7:423-440. CrossRef Medline

Diba K, Buzsáki G (2007) Forward and reverse hippocampal place-cell sequences during ripples. Nat Neurosci 10:1241-1242. CrossRef Medline

Diba K, Buzsaki G (2008) Hippocampal network dynamics constrain the time lag between pyramidal cells across modified environments. J Neurosci 28:13448-13456. CrossRef Medline

Diba K, Montgomery SM, Harris KD, Buzsáki G (2005) Identification of silicon probe irregularities using analysis of in vivo recordings. Soc Neurosci Abstr 31:275.10.

Diekelmann S, Born J (2010) The memory function of sleep. Nat Rev Neurosci 11:114-126. CrossRef Medline

Dolleman-Van der Weel MJ, Lopes da Silva FH, Witter MP (1997) Nucleus reuniens thalami modulates activity in hippocampal field CA1 through excitatory and inhibitory mechanisms. J Neurosci 17:5640-5650. Medline

Dragoi G, Buzsáki G (2006) Temporal encoding of place sequences by hippocampal cell assemblies. Neuron 50:145-157. CrossRef Medline

Eschenko O, Mölle M, Born J, Sara SJ (2006) Elevated sleep spindle density after learning or after retrieval in rats. J Neurosci 26:12914-12920. CrossRef Medline

Eschenko O, Ramadan W, Mölle M, Born J, Sara SJ (2008) Sustained increase in hippocampal sharp-wave ripple activity during slow-wave sleep after learning. Learn Mem 15:222-228. CrossRef Medline

Ferrarelli F, Huber R, Peterson MJ, Massimini M, Murphy M, Riedner BA, Watson A, Bria P, Tononi G (2007) Reduced sleep spindle activity in schizophrenia patients. Am J Psychiatry 164:483-492. CrossRef Medline

Ferrarelli F, Peterson MJ, Sarasso S, Riedner BA, Murphy MJ, Benca RM, Bria P, Kalin NH, Tononi G (2010) Thalamic dysfunction in schizophrenia suggested by whole-night deficits in slow and fast spindles. Am J Psychiatry 167:1339-1348. CrossRef Medline

Fogel SM, Smith CT (2011) The function of the sleep spindle: a physiologtical index of intelligence and a mechanism for sleep-dependent memory consolidation. Neurosci Biobehav Rev 35:1154-1165. CrossRef Medline

Freeman WJ (2007) Definitions of state variables and state space for braincomputer interface: Part 1. Multiple hierarchical levels of brain function. Cogn Neurodyn 1:3-14. CrossRef Medline

Fujisawa S, Buzsáki G (2011) A 4-Hz oscillation adaptively synchronizes prefrontal, VTA, and hippocampal activities. Neuron 72:153-165. CrossRef Medline

Gais S, Mölle M, Helms K, Born J (2002) Learning-dependent increases in sleep spindle density. J Neurosci 22:6830-6834. Medline

Geisler C, Robbe D, Zugaro M, Sirota A, Buzsáki G (2007) Hippocampal place cell assemblies are speed-controlled oscillators. Proc Natl Acad Sci U S A 104:8149-8154. CrossRef Medline

Gottesmann C (1973) Intermediate stages of sleep in the rat (in French). Rev Electroencephalogr Neurophysiol Clin 3:65-68. Medline

Gottselig JM, Bassetti CL, Achermann P (2002) Power and coherence of sleep spindle frequency activity following hemispheric stroke. Brain 125: 373-383. CrossRef Medline

Grosmark AD, Mizuseki K, Pastalkova E, Diba K, Buzsáki G (2012) REM sleep reorganizes hippocampal excitability. Neuron 75:1001-1007. CrossRef Medline

Hafting T, Fyhn M, Bonnevie T, Moser MB, Moser EI (2008) Hippocampus-independent phase precession in entorhinal grid cells. Nature 453:1248-1252. CrossRef Medline

Hahn TT, Sakmann B, Mehta MR (2007) Differential responses of hippocampal subfields to cortical up-down states. Proc Natl Acad Sci U S A 104:5169-5174. CrossRef Medline

Halassa MM, Siegle JH, Ritt JT, Ting JT, Feng G, Moore CI (2011) Selective optical drive of thalamic reticular nucleus generates thalamic bursts and cortical spindles. Nat Neurosci 14:1118-1120. CrossRef Medline

Hanlon EC, Faraguna U, Vyazovskiy VV, Tononi G, Cirelli C (2009) Effects of skilled training on sleep slow wave activity and cortical gene expression in the rat. Sleep 32:719-729. Medline

Harris KD, Henze DA, Hirase H, Leinekugel X, Dragoi G, Czurkó A, Buzsáki G (2002) Spike train dynamics predicts theta-related phase precession in hippocampal pyramidal cells. Nature 417:738-741. CrossRef Medline

Hazan L, Zugaro M, Buzsáki G (2006) Klusters, NeuroScope, NDManager: a free software suite neurophysiological data processing and visualization. J Neurosci Methods 155:207-216. CrossRef Medline

Herkenham M (1978) The connections of the nucleus reuniens thalami: evidence for a direct thalamo-hippocampal pathway in the rat. J Comp Neurol 177:589-610. CrossRef Medline

Isomura Y, Sirota A, Ozen S, Montgomery S, Mizuseki K, Henze DA, Buzsáki G (2006) Integration and segregation of activity in entorhinalhippocampal subregions by neocortical slow oscillations. Neuron 52:871882. CrossRef Medline

Jeewajee A, Barry C, O'Keefe J, Burgess N (2008) Grid cells and theta as oscillatory interference: electrophysiological data from freely moving rats. Hippocampus 18:1175-1185. CrossRef Medline

Ji D, Wilson MA (2007) Coordinated memory replay in the visual cortex and hippocampus during sleep. Nat Neurosci 10:100-107. CrossRef Medline

Johnson LA, Euston DR, Tatsuno M, McNaughton BL (2010) Stored-trace reactivation in rat prefrontal cortex is correlated with down-to-up state fluctuation density. J Neurosci 30:2650-2661. CrossRef Medline

Kamondi A, Acsády L, Wang XJ, Buzsáki G (1998) Theta oscillations in somata and dendrites of hippocampal pyramidal cells in vivo: activitydependent phase-precession of action potentials. Hippocampus 8:244261. CrossRef Medline

Khazipov R, Sirota A, Leinekugel X, Holmes GL, Ben-Ari Y, Buzsáki G (2004) Early motor activity drives spindle bursts in the developing somatosensory cortex. Nature 432:758-761. CrossRef Medline

Logothetis NK, Eschenko O, Murayama Y, Augath M, Steudel T, Evrard HC, Besserve M, Oeltermann A (2012) Hippocampal-cortical interaction during periods of subcortical silence. Nature 491:547-553. CrossRef Medline

Loomis AL, Harvey EN, Hobart G (1935) Potential rhythms of the cerebral cortex during sleep. Science 81:597-598. CrossRef Medline

Louie K, Wilson MA (2001) Temporally structured replay of awake hippocampal ensemble activity during rapid eye movement sleep. Neuron 29:145-156. CrossRef Medline

Maurer AP, Cowen SL, Burke SN, Barnes CA, McNaughton BL (2006) Organization of hippocampal cell assemblies based on theta phase precession. Hippocampus 16:785-794. CrossRef Medline

Mitra PP, Pesaran B (1999) Analysis of dynamic brain imaging data. Biophys J 76:691-708. CrossRef Medline

Mitzdorf U (1985) Current source-density method and application in cat 
cerebral cortex: investigation of evoked potentials and EEG phenomena. Physiol Rev 65:37-100. Medline

Miyamoto H, Hensch TK (2003) Reciprocal interaction of sleep and synaptic plasticity. Mol Interv 3:404-417. CrossRef Medline

Mizuseki K, Sirota A, Pastalkova E, Buzsáki G (2009) Theta oscillations provide temporal windows for local circuit computation in the entorhinalhippocampal loop. Neuron 64:267-280. CrossRef Medline

Mölle M, Yeshenko O, Marshall L, Sara SJ, Born J (2006) Hippocampal sharp wave-ripples linked to slow oscillations in rat slow-wave sleep. J Neurophysiol 96:62-70. CrossRef Medline

Montgomery SM, Buzsáki G (2007) Gamma oscillations dynamically couple hippocampal CA3 and CA1 regions during memory task performance. Proc Natl Acad Sci U S A 104:14495-14500. CrossRef Medline

Montgomery SM, Sirota A, Buzsáki G (2008) Theta and gamma coordination of hippocampal networks during waking and rapid eye movement sleep. J Neurosci 28:6731-6741. CrossRef Medline

Montgomery SM, Betancur MI, Buzsáki G (2009) Behavior-dependent coordination of multiple theta dipoles in the hippocampus. J Neurosci 29: 1381-1394. CrossRef Medline

Nadasdy Z, Hirase H, Czurko A, Csicsvari J, Buzsaki G (1999) Replay and time compression of recurring spike sequences in the hippocampus. J Neurosci 19:9497-9507. Medline

Nir Y, Staba RJ, Andrillon T, Vyazovskiy VV, Cirelli C, Fried I, Tononi G (2011) Regional slow waves and spindles in human sleep. Neuron 70: 153-169. CrossRef Medline

Nishida M, Walker MP (2007) Daytime naps, motor memory consolidation and regionally specific sleep spindles. PLoS One 2:e341. CrossRef Medline

O'Keefe J, Recce ML (1993) Phase relationship between hippocampal place units and the EEG theta rhythm. Hippocampus 3:317-330. CrossRef Medline

Peyrache A, Khamassi M, Benchenane K, Wiener SI, Battaglia FP (2009) Replay of rule-learning related neural patterns in the prefrontal cortex during sleep. Nat Neurosci 12:919-926. CrossRef Medline

Peyrache A, Battaglia FP, Destexhe A (2011) Inhibition recruitment in prefrontal cortex during sleep spindles and gating of hippocampal inputs. Proc Natl Acad Sci U S A 108:17207-17212. CrossRef Medline

Phillips KG, Bartsch U, McCarthy AP, Edgar DM, Tricklebank MD, Wafford KA, Jones MW (2012) Decoupling of sleep-dependent cortical and hippocampal interactions in a neurodevelopmental model of schizophrenia. Neuron 76:526-533. CrossRef Medline

Plante DT, Goldstein MR, Landsness EC, Peterson MJ, Riedner BA, Ferrarelli F, Wanger T, Guokas JJ, Tononi G, Benca RM (2013) Topographic and sex-related differences in sleep spindles in major depressive disorder: a high-density EEG investigation. J Affect Disord 146:120-125. CrossRef Medline

Schabus M, Gruber G, Parapatics S, Sauter C, Klösch G, Anderer P, Klimesch W, Saletu B, Zeitlhofer J (2004) Sleep spindles and their significance for declarative memory consolidation. Sleep 27:1479-1485. Medline

Schiffelholz T, Aldenhoff JB (2002) Novel object presentation affects sleepwake behavior in rats. Neurosci Lett 328:41-44. CrossRef Medline
Sejnowski TJ, Destexhe A (2000) Why do we sleep? Brain Res 886:208-223. CrossRef Medline

Siapas AG, Wilson MA (1998) Coordinated interactions between hippocampal ripples and cortical spindles during slow-wave sleep. Neuron 21:1123-1128. CrossRef Medline

Sirota A, Csicsvari J, Buhl D, Buzsáki G (2003) Communication between neocortex and hippocampus during sleep in rodents. Proc Natl Acad Sci U S A 100:2065-2069. CrossRef Medline

Steriade M (2000) Corticothalamic resonance, states of vigilance and mentation. Neuroscience 101:243-276. CrossRef Medline

Steriade M, Timofeev I (2003) Neuronal plasticity in thalamocortical networks during sleep and waking oscillations. Neuron 37:563-576. CrossRef Medline

Steriade M, Contreras D, Curró Dossi R, Nuñez A (1993a) The slow $(<1$ $\mathrm{Hz}$ ) oscillation in reticular thalamic and thalamocortical neurons: scenario of sleep rhythm generation in interacting thalamic and neocortical networks. J Neurosci 13:3284-3299. Medline

Steriade M, McCormick DA, Sejnowski TJ (1993b) Thalamocortical oscillations in the sleeping and aroused brain. Science 262:679-685. CrossRef Medline

Sullivan D, Csicsvari J, Mizuseki K, Montgomery S, Diba K, Buzsáki G (2011) Relationships between hippocampal sharp waves, ripples, and fast gamma oscillation: influence of dentate and entorhinal cortical activity. J Neurosci 31:8605-8616. CrossRef Medline

Tononi G, Cirelli C (2006) Sleep function and synaptic homeostasis. Sleep Med Rev 10:49-62. CrossRef Medline

Vukadinovic Z (2011) Sleep abnormalities in schizophrenia may suggest impaired trans-thalamic cortico-cortical communication: towards a dynamic model of the illness. Eur J Neurosci 34:1031-1039. CrossRef Medline

Wagner T, Axmacher N, Lehnertz K, Elger CE, Fell J (2010) Sleepdependent directional coupling between human neocortex and hippocampus. Cortex 46:256-263. CrossRef Medline

Wamsley EJ, Tucker MA, Shinn AK, Ono KE, McKinley SK, Ely AV, Goff DC, Stickgold R, Manoach DS (2012) Reduced sleep spindles and spindle coherence in schizophrenia: mechanisms of impaired memory consolidation? Biol Psychiatry 71:154-161. CrossRef Medline

Wilson MA, McNaughton BL (1994) Reactivation of hippocampal ensemble memories during sleep. Science 265:676-679. CrossRef Medline

Wilson S, Argyropoulos S (2012) Sleep in schizophrenia: time for closer attention. Br J Psychiatry 200:273-274. CrossRef Medline

Wolansky T, Clement EA, Peters SR, Palczak MA, Dickson CT (2006) Hippocampal slow oscillation: a novel EEG state and its coordination with ongoing neocortical activity. J Neurosci 26:6213-6229. CrossRef Medline

Wouterlood FG, Saldana E, Witter MP (1990) Projection from the nucleus reuniens thalami to the hippocampal region: light and electron microscopic tracing study in the rat with the anterograde tracer phaseoulus vulgaris-leucoagglutinin. J Comp Neurol 296:179-203. CrossRef Medline 